\title{
O nosso Professor Aziz
}

\section{DARIO LUIS BORELLI}

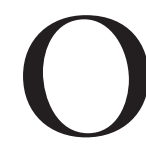

PROFESSOR Aziz Ab'Sáber sempre foi presença constante nas páginas de nossa revista ESTUDOS AVANÇADOS. Quando não brindava o periódico com artigos exclusivos de sua autoria, indicava autores, concedia entrevistas, discutia e fazia críticas, sugeria abordagens e temas de dossiês.

Foi assim desde 1989, quando a revista trouxe a lume sua primeira colaboração, "Zoneamento ecológico e econômico da Amazônia: questões de escala e método", em que reivindica a constituição de uma equipe multidisciplinar, formada por agrônomos, geógrafos, ecólogos, engenheiros florestais e cartógrafos, "sob um critério basicamente ecodesenvolvimentista e independente de injunções políticas circunstanciais", para a elaborar o que chamou master plan de validade amazônica.

Em 1990, publicou o conjunto de artigos sobre o "Projeto Floram", retomado ainda em número de 1996. A recepção da crítica especializada atestou a originalidade da proposta de reflorestamento para o Brasil, liderada pelo pesquisador.

O sertão nordestino e os sertanejos foram preocupações cotidianas em sua vida, mas se acentuaram no final da década de 1990, quando sugeriu à ESTUDOS AVANÇADOS um dossiê dedicado ao assunto.

Quando a Universidade de São Paulo completou 60 anos de sua fundação, em 1994, o discípulo reconheceu a importância do mestre em sua formação acadêmica, escrevendo o perfil "Pierre Monbeig: a herança intelectual de um geógrafo".

Nos anos 2000, a Amazônia brasileira aparece novamente no centro de suas preocupações como cientista e militante ambiental. Além de suas notáveis contribuições teórico-metodológicas sobre o tema, houve manifestações críticas diante da falta de entendimento das autoridades públicas, seja em relação à seca e as queimadas sucessivas em Roraima, seja em relação ao impasse na Reserva Indígena Raposa/Serra do Sol, também em Roraima.

Assim se passaram mais de 20 anos e a revista guarda com carinho lembranças de uma convivência amistosa, estimulante e animadora. Seu falecimento no último dia 16 de março, em São Paulo, privou EsTUDOS AVANÇADOS de um de seus colaboradores e conselheiros mais fecundos.

A exemplo das homenagens já feitas a personalidades como Florestan Fer- 
nandes e John von Neumann (número 26, 1996), e, mais recentemente, Claude Lévi-Strauss (número 67, 2009), ESTUDOS AVANÇADOS pretende colher entre seus inúmeros parceiros e admiradores, no Brasil e no exterior, depoimentos prestados em sua honra, incluindo nesta justa homenagem o artigo ainda inédito de sua autoria “O legado de Madame Emperaire no estudo da Lapa Vermelha".

A relação completa dos artigos do Professor Aziz publicados em ESTUDOS AVANÇADOS é apresentada a seguir (todos podem ser acessados na íntegra no site do periódico na Scientific Electronic Library Online - www.scielo.br):

- Zoneamento ecológico e econômico da Amazônia: questões de escala e método, v.3, n.5, p.4-20, 1989.

- Projeto Floram: Um plano diferencial para o Brasil, v.4, n.9, p.19-63, 1990.

- Identificação de áreas para o florestamento no espaço total do Brasil (com José Goldemberg, Leopoldo Rodés e Werner Zulauf), v.4, n.9, p.63-119, 1990.

- Projeto Floram: estratégias e plano de ação (com Antonio S. Rensi Coelho, Geraldo Forbes, Jacques Marcovitch, James Wright, José Goldemberg, Leopold Rodés, Luiz G. Barrichelo, Mauro Antonio de Morais Victor, Nelson Barbosa e Werner Zulauf), v.4, n.9, p.120-148, 1990.

- Floram: Nordeste seco, v.4, n.9, p.149-174, 1990.

- Pierre Monbeig: a herança intelectual de um geógrafo, v.8, n.22, p.221-32, 1994.

- O Floram e desenvolvimento sustentável (com Werner Zulauf e Leopoldo Rodés), v.10, n.27, p.307-316, 1996.

- Roraima: os paradoxos de um grande incêndio ao fim do milênio, v.12, n.33, p.22731, 1998.

- Sertões e sertanejos: uma geografia humana sofrida, v.13, n.36, p.7-59, 1999.

- Nordeste sertanejo: a região semi-árida mais povoada do mundo (fragmentos de leitura), v.13, n.36, p.60-68, 1999.

- Bibliografia do Nordeste seco, v.13, n.36, p.115-143, 1999.

- Bases para o estudo dos ecossistemas da Amazônia brasileira, v.16, n.45, p.7-30, 2002.

- Problemas da Amazônia brasileira (entrevista a Dario Luis Borelli et al.), v.19, n.53, p.7-35, 2005.

- O paleodeserto de Xique-Xique, v.20, n.56, p.301-308, 2006.

- A propósito da periodicidade climato-hidrológica que vem provocando grandes crise em Santa Catarina, v.23, n.67, p.299-306, 2009.

- A região da Reserva Indígena Raposa/Serra do Sol. Prévias para o seu entendimento, v.23, n.65, p.165-174, 2009.

- Zoneamento fisiográfico e ecológico do espaço total da Amazônia brasileira, v.24, n.68, p.15-24, 2010.

Dario Luis Borelli é editor assistente de ESTUDOS AVANÇADOS e professor de Comunicação Social das Faculdades Integradas Rio Branco. @-dariolb@usp.br 


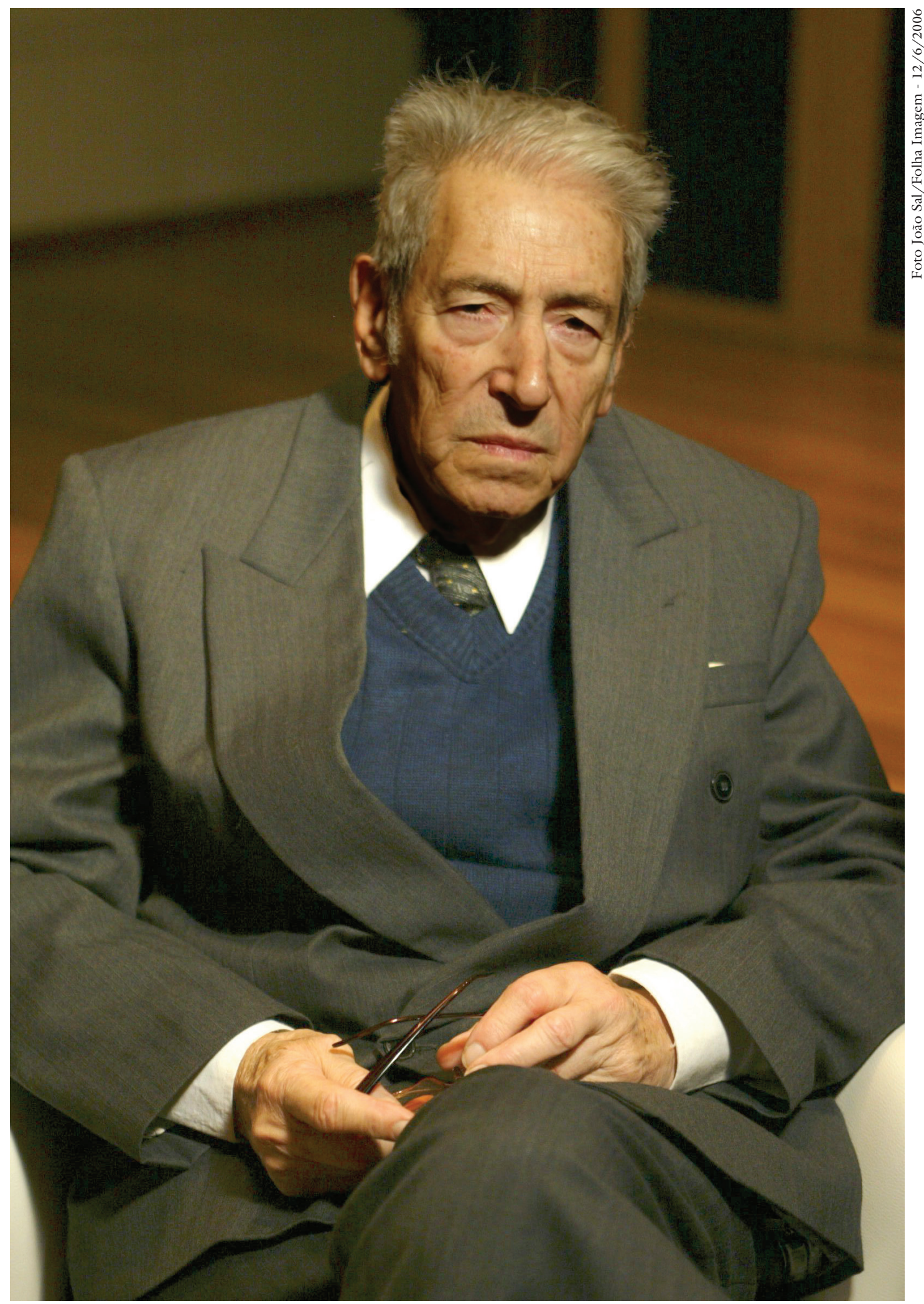

Aziz Ab'Sáber (1924-2012) foi Professor Honorário do Instituto de Estudos Avançados da USP. 


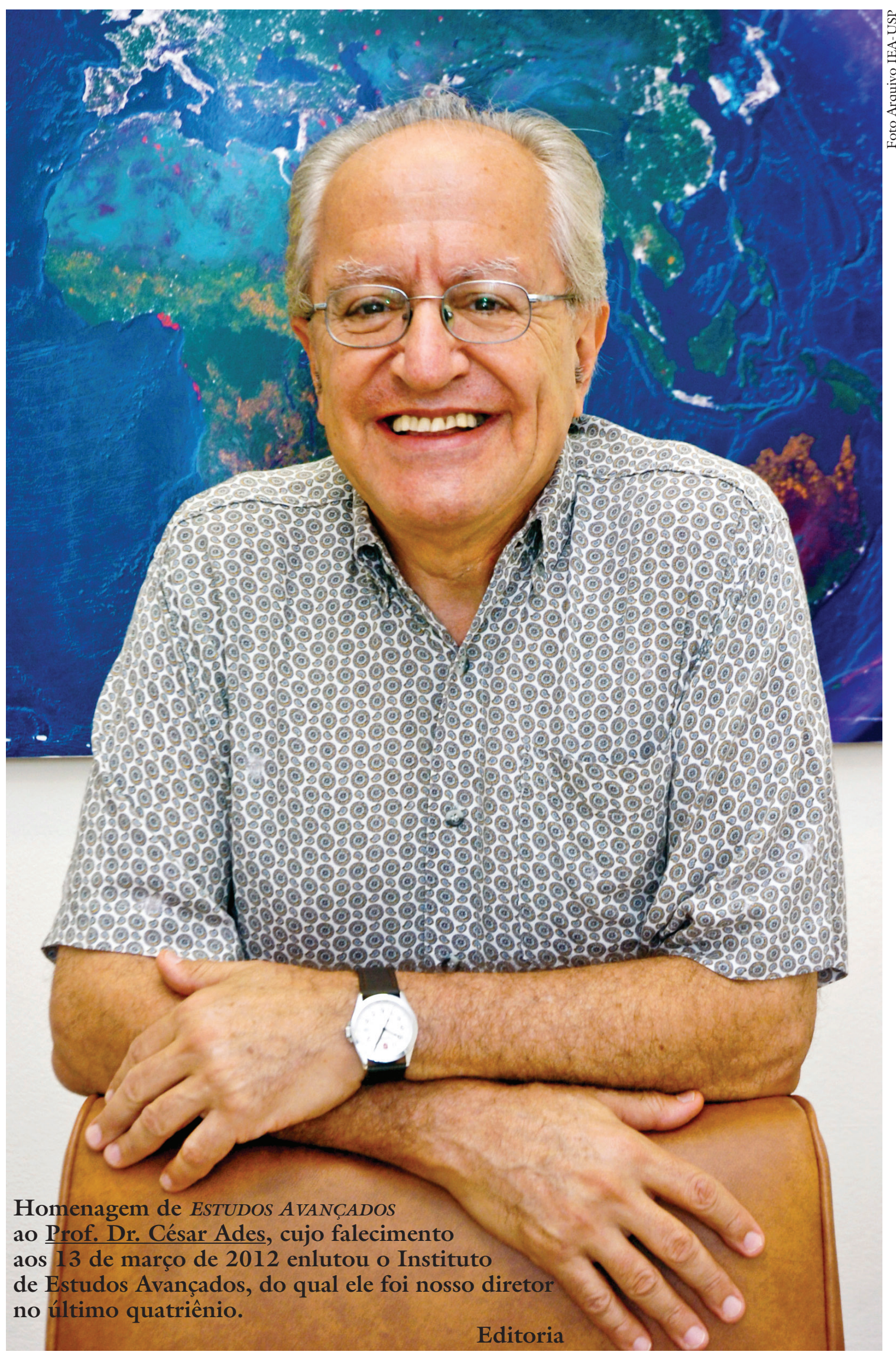

